\title{
Composição química, fracionamento de carboidratos e proteínas e digestibilidade in vitro de forrageiras tropicais em diferentes idades de corte ${ }^{1}$
}

\author{
Paula Andrea Toro Velásquez ${ }^{2}$, Telma Teresinha Berchielli ${ }^{3,4}$, Ricardo Andrade Reis ${ }^{3,4}$, \\ Astrid Rivera Rivera ${ }^{2}$, Paulo Henrique Moura Dian², Izabelle Auxiliadora Molina de Almeida \\ Teixeira $^{3}$
}

${ }^{1}$ Pesquisa financiada pela FAPESP.

2 Programa de Pós-graduação em Zootecnia - UNESP/Jaboticabal.

${ }^{3}$ Departamento de Zootecnia - FCAV - UNESP/Jaboticabal.

${ }^{4}$ Bolsista de Produtividade em Pesquisa do CNPq.

RESUMO - Objetivou-se avaliar o valor nutritivo de três espécies forrageiras tropicais: capim-tanzânia (Panicum maximum Jacq.), capim-marandu (Brachiaria brizantha) e capim-tifton 85 (Cynodon spp), em duas épocas do ano (janeiromarço e abril-junho) e em três idades de rebrota (28, 35 e 42 dias), por meio da composição química, do fracionamento de proteínas e carboidratos e da digestibilidade in vitro da matéria seca (DIVMS) e da matéria orgânica (DIVMO). O capim-marandu destacou-se no período de janeiro-março, com menores conteúdos de parede celular e fração B2 dos carboidratos e maiores valores de proteína bruta, fração A + B1, DIVMS e DIVMO, em comparação aos capins tanzânia e tifton 85, independentemente da idade de corte. O aumento da concentração de parede celular em detrimento ao conteúdo celular com o avanço da maturidade das plantas foi evidente no capim-marandu no período de janeiro-março, quando foram observados maior valor da fração B2, maior conteúdo de fibra em detergente neutro (FDN) e menor concentração da fração carboidratos não-fibrosos. No período de abril-junho, a composição em parede celular não apresentou diferenças evidentes com aumento da idade, devido às condições ambientais observadas. O capim-tanzânia apresenta, de modo geral, baixos valores de parede celular e altos valores de carboidratos não-fibrosos, DIVMS e DIVMO nesse período, seguido pelos capins marandu e tifton 85, respectivamente.

Palavras-chave: capim-marandu, capim-tanzânia, capim-tifton 85, conteúdo celular, parede celular, valor nutritivo

\section{Chemical composition, fractionation of carbohydrates and crude protein and in vitro digestibility on tropical forages in the different cutting ages}

\begin{abstract}
This trial was conducted with the objective of evaluating the nutritive value of three tropical forage species: tanzania grass (Panicum maximum Jacq.), marandu grass (Brachiaria brizantha) and Tifton 85 bermudagrass (Cynodon spp) in two different periods of the year (January-March and April-June) and in three cutting ages (28, 35 and 42 days), based on the chemical composition, protein and carbohydrate fractions, and in vitro digestibility of dry matter (DMD) and organic matter (OMD). Marandu grass, in the period January-March, had the lowest cellular wall contents and B2 fraction of carbohydrates, and higher values of crude protein, A + B1 fraction, DMD and OMD in comparison to tanzania grass and Tifton 85 bermudagrass, regardless of the cutting age. The increase of concentration of the cell wall in detriment to the cell content as plant maturity advanced was evident in marandu grass during January-March when higher values of B2 fraction, higher content of neutral detergent fiber and lower concentrations of non fibrous carbohydrate fractions were observed. In April-June period, the cellular wall contents did not show evident differences as age increased due to environmental conditions. The tanzania grass presents, in general, lower values of the cell wall and higher values of non fibrous carbohydrate, DMD and OMD during this period, followed by marandu grass and Tifton 85 bermudagrass, respectively.
\end{abstract}

Key Words: cell content, cell wall, marandu grass, nutritive value, tanzania grass, tifton 85 bermudagrass

\section{Introdução}

O valor nutritivo da forragem pode variar entre espécies e partes da planta e se relaciona diretamente ao consumo (Mertens, 1994). Os estudos que caracterizam os pastos em termos de composição química e digestibilidade são relevantes na avaliação de forrageiras, pois auxiliam na indicação da necessidade de suplementação da dieta em determinadas épocas para algumas categorias de animais. Ainda, o estudo do valor nutritivo da forragem contribui para a identificação dos possíveis pontos que restringem o consumo de nutrientes e a produção animal (Brâncio et al., 2002).

Recebido em 29/4/2008 e aprovado em 20/5/2009.

Correspondências devem ser enviadas para:phmdian@yahoo.com.br 
À medida que a idade fisiológica da planta avança, aumentam as porcentagens de celulose, hemicelulose e lignina, reduzindo a proporção dos nutrientes potencialmente digestíveis (carboidratos solúveis, proteínas, minerais e vitaminas), que representam uma queda acentuada na digestibilidade (Reis et al., 2005). Além do aumento da concentração de fibra nas hastes e na maioria das folhas, a concentração de fibras também é maior na forragem total devido ao decréscimo da relação folha/ haste, decorrente da maturidade das plantas (Buxton \& Redfearn, 1997).

As vantagens da utilização da técnica in vitro na avaliação do valor nutritivo dos alimentos para ruminantes estão na sua rapidez, na uniformidade físico-química do local de fermentação e na conveniência de se manter poucos animais fistulados, além de serem menos onerosas. Essas técnicas de laboratório podem ser eficientes desde que sejam facilmente reproduzíveis e altamente correlacionadas a resultados obtidos in vivo (Getachew et al., 1998).

Objetivou-se neste trabalho avaliar o valor nutritivo de três espécies forrageiras tropicais: capim-tanzânia (Panicum maximum Jacq.), capim-marandu (Brachiaria brizantha) e capim-tifton 85 (Cynodon spp), em duas épocas do ano (janeiro-março e abril-junho) e em três idades de rebrota (28, 35 e 42 dias), por meio da composição química, do fracionamento de proteínas e carboidratos e da digestibilidade in vitro da matéria seca e matéria orgânica.

\section{Material e Métodos}

O trabalho foi realizado na Faculdade de Ciências Agrárias e Veterinárias- UNESP, Campus de Jaboticabal, Estado de São Paulo, Brasil, localizado a $21^{\circ} 15^{\prime} 22^{\prime \prime}$ de latitude sul e $48^{\circ} 18^{\prime} 58^{\prime \prime}$ de longitude a oeste de Greenwich e a uma altitude de $595 \mathrm{~m}$. O local apresenta temperatura média anual de $22,3^{\circ} \mathrm{C}$ e precipitação pluvial média de $1.400 \mathrm{~mm}$, com $85 \%$ do total das chuvas concentradas nos meses de outubro a março. Nos períodos experimentais (janeiro-março e abril-junho), o total de chuva foi 784,8 mm, com temperatura máxima e mínima de 31,8 e $14,4^{\circ} \mathrm{C}$, respectivamente (Tabela 1 ). O período experimental teve duração de 5 meses, de janeiro a junho de 2005.

A área experimental ocupou um total de $264 \mathrm{~m}^{2}$, sendo $88 \mathrm{~m}^{2}$ destinados a cada espécie $(8 \times 11 \mathrm{~m})$. Cada área foi dividida em três canteiros, um para cada idade de corte (28, 35 e 42 dias). No início do experimento e depois de cada corte para amostragem, todas as parcelas foram fertilizadas com $60 \mathrm{~kg} \mathrm{~N} / \mathrm{ha}$. A fim de garantir a persistência das espécies, os cortes foram realizados em diferentes alturas de manejo (capim-tanzânia, 30 cm; capim-marandu, 25 cm; capim-tifton 85, $15 \mathrm{~cm}$ ).

A amostragem dos capins foi realizada adotando-se um quadrado de $1 \mathrm{~m}^{2}$ de área, lançado ao acaso em três pontos do canteiro representativos da área. A forragem encontrada dentro da área do quadrado foi cortada nas alturas de manejo das espécies. Após a coleta, as amostras foram présecas em estufa com circulação forçada de ar a $55^{\circ} \mathrm{C}$ durante 72 horas. As amostras obtidas nos três pontos do canteiro foram homogeneizadas para representar a área, gerando uma amostra composta, a qual se trabalhou com duas repetições em todas as análises realizadas. Posteriormente, o material foi pesado e processado em moinho tipo Willey com peneira de malha de $1 \mathrm{~mm}$.

As amostras pré-secas foram utilizadas na determinação do conteúdo de matéria seca (MS), matéria mineral (MM), extrato etéreo (EE) e proteína bruta (PB) de acordo com AOAC (1990). As avaliações da fibra em detergente neutro (FDN), fibra em detergente neutro corrigida para cinzas e proteína (FDNcp), fibra em detergente ácido (FDA) e lignina seguiram o protocolo descrito por Van Soest \& Robertson (1985).

A digestibilidade in vitro foi determinada pelo procedimento de Tilley \& Terry (1963), com dois estágios de incubação de 48 horas. No primeiro estágio, as amostras (secas e moídas) foram pesadas $(0,5 \mathrm{~g})$ e colocadas em tubos de ensaio (de $100 \mathrm{~mL}$ de capacidade, com rolhas de borracha equipadas com válvulas de Bunsen para o escape dos gases), nos quais foram adicionados $40 \mathrm{~mL}$ de solução tampão McDougal (McDougal, 1949) e 10 mL de líquido ruminal (coletado em jejum de um animal doador, adaptado por 10 dias à forragem verde). A inoculação dos tubos foi realizada com constante borbulhado de $\mathrm{CO}_{2}$ incubados em estufa com circulação de ar forçado a $39^{\circ} \mathrm{C}$ por 48 horas. Os tubos foram agitados durante o primeiro estágio às 2 , 4, 6, 8, 12, 16, 24 e 36 horas após a incubação para permitir o escape dos gases formados.

Tabela 1 - Dados meteorológicos mensais da área no período experimental

\begin{tabular}{lcccc}
\hline \multirow{2}{*}{ Mês } & \multicolumn{3}{c}{ Temperatura $\left({ }^{\circ} \mathrm{C}\right)$} \\
\cline { 2 - 5 } & Máxima & Mínima & Média & $\begin{array}{c}\text { Precipitação } \\
(\mathrm{mm})\end{array}$ \\
\hline Janeiro & 29,6 & 20,7 & 24,1 & 358,5 \\
Fevereiro & 31,8 & 18,7 & 24,3 & 81,2 \\
Março & 31,0 & 19,7 & 24,3 & 128,0 \\
Abril & 30,9 & 19,0 & 23,9 & 59,6 \\
Maio & 27,9 & 15,1 & 20,6 & 127,4 \\
Junho & 27,0 & 14,4 & 19,7 & 30,1 \\
\hline
\end{tabular}


Após a primeira etapa, foram adicionados em cada tubo $2 \mathrm{~mL}$ de $\mathrm{HCl}$ a $6 \mathrm{~N}$ ( $\mathrm{HCl}$ concentrado $12 \mathrm{~N}$, com igual quantidade de água destilada (1:1)), e $6 \mathrm{~mL}$ de pepsina a $5 \%(50 \mathrm{~g} / \mathrm{L})$, que foram incubados novamente por mais 48 horas a $39^{\circ} \mathrm{C}$, repetindo o processo de agitação descritos na primeira etapa. Após a digestão com pepsina, o conteúdo dos tubos foi transferido para cadinhos previamente pesados. Os tubos foram lavados com água destilada quente para a recuperação total das partículas remanescentes. Após a filtração, os cadinhos foram levados à estufa a $105^{\circ} \mathrm{C}$ por 12 horas, esfriados em dessecador e pesados, e finalmente levados para mufla a $550^{\circ} \mathrm{C}$ por 3 horas.

O fracionamento da proteína foi realizado de acordo com Licitra et al. (1996), ou seja, a fração A (NNP) foi obtida por diferença entre o nitrogênio total e o nitrogênio insolúvel em ácido tricloroacético. O nitrogênio insolúvel total foi determinado a partir do tratamento de $0,5 \mathrm{~g}$ da amostra com tampão borato-fosfato. O nitrogênio solúvel total foi obtido pela diferença entre o nitrogênio total menos o nitrogênio insolúvel no tampão borato-fosfato. A fração $B_{1}$ foi determinada pela diferença entre a fração do nitrogênio solúvel total menos fração $A$. A fração $B_{3}$ foi calculada pela diferença entre o nitrogênio insolúvel em detergente neutro (NIDN) e o nitrogênio insolúvel em detergente ácido (NIDA), determinados por meio da fervura de 0,5 g da amostra, com solução detergente neutra e ácida durante uma hora, respectivamente, com análise dos resíduos também para nitrogênio. A fração C foi considerada como o nitrogênio insolúvel em detergente ácido (NIDA), e a fração $\mathrm{B}_{2}$, determinada pela diferença entre 100 e as frações $A, B_{1}, B_{3}$ e $C$, como porcentagem da proteína.

Os carboidratos totais (CT) e os não-fibrosos (CNF) foram determinados segundo Sniffen et al. (1992), pelas expressões CT $=100-(\% \mathrm{~PB}+\% \mathrm{EE}+\% \mathrm{MM})$, e CNF $=100$ - (\%PB + \%EE + \%FDNcp + MM), em que FDNcp equivale à fibra em detergente neutro corrigida para cinzas e proteínas. A fração $B_{2}$ foi calculada pela diferença entre FDNcp Fração C (Sniffen et al., 1992) e a C, pela porcentagem de lignina multiplicada por 2,4 (Sniffen et al., 1992).

Os dados foram analisados por fatorial $3 \times 3$ com os fatores: espécies (capins tanzânia, marandu e tifton 85) e idades de corte (28, 35 e 42 dias), com duas repetições (provenientes da amostra composta), em esquema de parcelas subdivididas no tempo (janeiro-março e abriljunho). As médias foram confrontadas pelo teste $\mathrm{T}$ aplicando-se o nível de 95\% de confiança, obtido pelo módulo estatístico do programa SAS (2001).

\section{Resultados e Discussão}

Considerando que a composição química das plantas forrageiras que formam uma pastagem pode ser alterada de acordo com as condições de meio e manejo impostas e, analisando as condições experimentais deste trabalho: temperatura e precipitação (Tabela 1), alturas de corte e períodos de rebrota avaliados, esses fatores resultaram em composição química mais favorável, ou seja, menores proporções da fração fibrosa (Tabela 2) e maiores de carboidratos não-fibrosos nas espécies de hábito de crescimento cespitoso (capins tanzânia e marandu). Esse fato pode estar relacionado a eliminação dos meristemas apicais nos capins tanzânia e marandu, estimulando o surgimento de tecidos novos nas plantas desde as gemas basais, fato que não aconteceu com o capim-tifton 85 . Ressalta-se que, em decorrência de suas características de crescimento estolonífero e com a altura de corte de $15 \mathrm{~cm}$, ocorreu a preservação dos meristemas apicais, com pequena renovação de tecidos foliares, e concomitante acúmulo de material morto na base das plantas.

O espessamento da parede celular secundária com a maturação dos tecidos vegetais aumenta a concentração de fibra em detergente neutro em detrimento do conteúdo celular (Wilson, 1993; 1997). Esse comportamento foi evidente no capim-marandu no período de janeiro-março, quando foi observado aumento nos teores de fibra em detergente neutro, fibra em detergente neutro corrigida para cinzas e proteínas e fibra em detergente ácido conforme a maturação da forragem, com consequente aumento das frações de carboidratos totais e fração $B_{2}$. Foi observada também diminuição da fração carboidratos não-fibrosos com o avanço da idade de corte e com aumento dos teores de lignina no capim-marandu.

Ao contrário, no capim-tanzânia não houve aumento da proporção de parede celular com o aumento da idade de rebrota em janeiro-março, uma vez que se tornaram menores os valores de fibra em detergente neutro, fibra em detergente neutro corrigida para cinzas e proteínas e fração $B_{2}$ e maiores os de carboidratos não-fibrosos aos 42 dias de rebrota. Já o capim-tifton 85, em decorrência do manejo implementado, nos desdobramentos espécie $\times$ idade de corte, não apresentou diferença na maioria das variáveis.

De maneira geral, no período de abril-junho, o capimmarandu apresentou aumento nos teores de fibra em detergente neutro, fibra em detergente neutro corrigida para cinzas e proteínas, fibra em detergente ácido, carboidratos totais, lignina e frações $B_{2}$ e $C$ e redução nos 
Tabela 2 - Concentração de parede celular e fracionamento de carboidratos no período de janeiro a março e abril a junho

\begin{tabular}{|c|c|c|c|c|c|c|c|c|}
\hline \multirow[b]{2}{*}{ Éроса } & \multirow[b]{2}{*}{ Espécie } & \multirow[t]{2}{*}{ Fração(\% MS) } & \multicolumn{6}{|c|}{ Idade de corte da espécie ${ }^{1}$} \\
\hline & & & & 28 & & 35 & & 42 \\
\hline \multirow[t]{3}{*}{ Janeiro a março } & Capim-marandu & & 53,24 & $\pm 0,43 \mathrm{Db}$ & 51,21 & $\pm 0,34 \mathrm{Ec}$ & 58,74 & $\pm 1,10 \mathrm{Ca}$ \\
\hline & Capim-tifton 85 & & 68,33 & $\pm 0,19 \mathrm{Ab}$ & 69,59 & $\pm 0,44 \mathrm{Aa}$ & 69,02 & $\pm 0,74 \mathrm{Aab}$ \\
\hline & Capim-tanzânia & Fibra em & 65,93 & $\pm 0,34 \mathrm{Ba}$ & 65,25 & $\pm 0,01 \mathrm{Bb}$ & 59,57 & $\pm 1,16 \mathrm{Cc}$ \\
\hline \multirow[t]{3}{*}{ Abril a junho } & Capim-marandu & detergente & 62,82 & $\pm 0,45 \mathrm{Cc}$ & 64,08 & $\pm 0,05 \mathrm{Cb}$ & 65,70 & $\pm 0,35 \mathrm{Ba}$ \\
\hline & Capim-tifton 85 & neutro & 68,88 & $\pm 1,87 \mathrm{Aa}$ & 68,94 & $\pm 0,81 \mathrm{Aa}$ & 70,27 & $\pm 0,33 \mathrm{Aa}$ \\
\hline & Capim-tanzânia & & 65,24 & $\pm 0,40 \mathrm{Ba}$ & 59,38 & $\pm 0,06 \mathrm{Dc}$ & 60,43 & $\pm 0,55 \mathrm{Cb}$ \\
\hline \multirow[t]{3}{*}{ Janeiro a março } & Capim-marandu & FDNcp & 42,35 & $\pm 0,69 \mathrm{Dc}$ & 47,19 & $\pm 0,85 \mathrm{~Eb}$ & 54,31 & $\pm 1,45 \mathrm{Ba}$ \\
\hline & Capim-tifton 85 & & 62,06 & $\pm 0,27 \mathrm{Aa}$ & 62,54 & $\pm 1,19$ Aa & 61,97 & $\pm 1,30 \mathrm{Aa}$ \\
\hline & Capim-tanzânia & & 60,17 & $\pm 0,37 \mathrm{Ba}$ & 59,36 & $\pm 0,39 \mathrm{Ca}$ & 53,61 & $\pm 1,63 \mathrm{Bb}$ \\
\hline \multirow[t]{3}{*}{ Abril a junho } & Capim-marandu & & 59,29 & $\pm 0,94 \mathrm{BCc}$ & 60,99 & $\pm 0,02 \mathrm{Bb}$ & 63,11 & $\pm 0,25 \mathrm{Aa}$ \\
\hline & Capim-tifton 85 & & 60,60 & $\pm 0,67 \mathrm{Bb}$ & 58,86 & $\pm 0,30$ Cc & 63,18 & $\pm 0,57 \mathrm{Aa}$ \\
\hline & Capim-tanzânia & & 58,96 & $\pm 0,46 \mathrm{Ca}$ & 52,10 & $\pm 0,07 \mathrm{Dc}$ & 54,88 & $\pm 0,80 \mathrm{Bb}$ \\
\hline \multirow[t]{3}{*}{ Janeiro a março } & Capim-marandu & FDA & 20,97 & $\pm 0,49 \mathrm{Ec}$ & 26,44 & $\pm 0,10 \mathrm{~Eb}$ & 33,33 & $\pm 0,10 \mathrm{Aa}$ \\
\hline & Capim-tifton 85 & & 31,60 & $\pm 0,54 \mathrm{Da}$ & 31,60 & $\pm 0,21 \mathrm{BCa}$ & 31,75 & $\pm 0,54 \mathrm{Da}$ \\
\hline & Capim-tanzânia & & 33,15 & $\pm 0,04 \mathrm{Ba}$ & $31,89=$ & $\pm 0,48 \mathrm{ABb}$ & 33,48 & $\pm 0,63 \mathrm{Aa}$ \\
\hline \multirow[t]{3}{*}{ Abril a junho } & Capim-marandu & & 32,42 & $\pm 0,03 \mathrm{Ca}$ & 32,89 & $\pm 0,77 \mathrm{Aa}$ & 32,89 & $\pm 0,09 \mathrm{Ba}$ \\
\hline & Capim-tifton 85 & & 34,07 & $\pm 0,12 \mathrm{Aa}$ & 30,34 & $\pm 0,16 \mathrm{Dc}$ & 31,86 & $\pm 0,04 \mathrm{Db}$ \\
\hline & Capim-tanzânia & & 34,73 & $\pm 0,52 \mathrm{Aa}$ & 31,23 & $\pm 0,06 \mathrm{Cc}$ & 32,60 & $\pm 0,04 \mathrm{Cb}$ \\
\hline \multirow[t]{3}{*}{ Janeiro a março } & Capim-marandu & & 70,56 & $\pm 0,50 \mathrm{~Eb}$ & 74,05 & $\pm 0,24 \mathrm{DEa}$ & 74,18 & $\pm 0,33 \mathrm{Da}$ \\
\hline & Capim-tifton 85 & & 78,19 & $\pm 0,05 \mathrm{Bb}$ & 77,92 & $\pm 0,38 \mathrm{Bb}$ & 78,83 & $\pm 0,26 \mathrm{Aa}$ \\
\hline & Capim-tanzânia & Carboidratos & 80,04 & $\pm 0,19 \mathrm{Aa}$ & 79,39 & $\pm 0,17 \mathrm{Ab}$ & 79,13 & $\pm 0,08 \mathrm{Ab}$ \\
\hline \multirow[t]{3}{*}{ Abril a junho } & Capim-marandu & totais & 74,45 & $\pm 0,27 \mathrm{Dc}$ & 76,89 & $\pm 0,42 \mathrm{Cb}$ & 78,02 & $\pm 0,20 \mathrm{Ba}$ \\
\hline & Capim-tifton 85 & & 76,47 & $\pm 0,72 \mathrm{Ca}$ & 74,11 & $\pm 0,25 \mathrm{Db}$ & 76,52 & $\pm 0,59 \mathrm{Ca}$ \\
\hline & Capim-tanzânia & & 75,18 & \pm 0,59CDa & 73,27 & $\pm 0,42 \mathrm{~Eb}$ & 74,44 & $\pm 1,32 \mathrm{CDab}$ \\
\hline \multirow[t]{3}{*}{ Janeiro a março } & Capim-marandu & & 28,21 & $\pm 1,20 \mathrm{Aa}$ & 26,87 & $\pm 1,08 \mathrm{Aa}$ & 19,88 & $\pm 1,78 \mathrm{Bb}$ \\
\hline & Capim-tifton 85 & & 16,13 & $\pm 0,22 \mathrm{Ca}$ & 15,38 & $\pm 0,80 \mathrm{Ca}$ & 16,86 & $\pm 1,55 \mathrm{Ba}$ \\
\hline & Capim-tanzânia & Carboidratos & 19,88 & $\pm 0,57 \mathrm{Bb}$ & 20,04 & $\pm 0,56 \mathrm{Bb}$ & 25,52 & $\pm 1,70 \mathrm{Aa}$ \\
\hline \multirow[t]{3}{*}{ Abril a junho } & Capim-marandu & não-fibrosos & 15,16 & $\pm 1,20 \mathrm{Ca}$ & 15,90 & $\pm 0,44 \mathrm{Ca}$ & 14,92 & $\pm 0,05 \mathrm{Ca}$ \\
\hline & Capim-tifton 85 & & 15,88 & $\pm 1,39 \mathrm{Ca}$ & 15,26 & $\pm 0,06 \mathrm{Ca}$ & 13,34 & $\pm 1,15 \mathrm{Da}$ \\
\hline & Capim-tanzânia & & 16,22 & $\pm 0,13 \mathrm{Cc}$ & 21,17 & $\pm 0,49 \mathrm{Ba}$ & 19,57 & $\pm 0,52 \mathrm{Bb}$ \\
\hline \multirow[t]{3}{*}{ Janeiro a março } & Capim-marandu & Fraçao B & 53,01 & $\pm 1,91 \mathrm{Cc}$ & 56,13 & $\pm 1,12 \mathrm{Db}$ & 65,33 & \pm 3,36ВСа \\
\hline & Capim-tifton 85 & & 68,50 & $\pm 0,73 \mathrm{Aa}$ & $69,02=$ & $\pm 1,86 \mathrm{ABa}$ & 70,30 & $\pm 1,51 \mathrm{Ba}$ \\
\hline & Capim-tanzânia & & 68,70 & $\pm 0,16 \mathrm{Aa}$ & 68,26 & $\pm 0,32 \mathrm{Ba}$ & 60,32 & $\pm 2,11 \mathrm{Cb}$ \\
\hline \multirow[t]{3}{*}{ Abril a junho } & Capim-marandu & & 69,86 & $\pm 0,91 \mathrm{Ab}$ & 70,12 & $\pm 0,74 \mathrm{Ab}$ & 72,14 & $\pm 0,05 \mathrm{Aa}$ \\
\hline & Capim-tifton 85 & & 64,00 & $\pm 2,31 \mathrm{Bb}$ & 68,02 & $\pm 0,18 \mathrm{Ba}$ & 70,36 & $\pm 1,65 \mathrm{ABa}$ \\
\hline & Capim-tanzânia & & 67,41 & $\pm 1,99 \mathrm{Aa}$ & 61,79 & $\pm 1,85 \mathrm{Cc}$ & 64,72 & $\pm 0,48 \mathrm{Cb}$ \\
\hline \multirow[t]{3}{*}{ Janeiro a março } & Capim-marandu & Fração C & 7,02 & $\pm 0,51 \mathrm{Ca}$ & 7,61 & $\pm 0,22 \mathrm{Da}$ & 7,89 & $\pm 1,08 \mathrm{BCa}$ \\
\hline & Capim-tifton 85 & & 10,89 & $\pm 1,03 \mathrm{Ba}$ & $11,25=$ & $\pm 0,73 \mathrm{ABa}$ & 8,33 & $\pm 0,39 \mathrm{Bb}$ \\
\hline & Capim-tanzânia & & 6,47 & $\pm 0,49 \mathrm{Cb}$ & $6,51=$ & $\pm 0,98 \mathrm{Dab}$ & 7,45 & $\pm 0,01 \mathrm{Ca}$ \\
\hline \multirow[t]{3}{*}{ Abril a junho } & Capim-marandu & & 9,79 & $\pm 0,63 \mathrm{Ba}$ & 9,20 & $\pm 0,28 \mathrm{Cab}$ & 8,75 & $\pm 0,15 \mathrm{Bb}$ \\
\hline & Capim-tifton 85 & & 15,26 & $\pm 0,69 \mathrm{Aa}$ & 11,40 & $\pm 0,33 \mathrm{Ac}$ & 12,22 & $\pm 0,28 \mathrm{Ab}$ \\
\hline & Capim-tanzânia & & 11,02 & $\pm 1,99 \mathrm{Ba}$ & 9,33 & $\pm 1,35 \mathrm{BCa}$ & 9,00 & $\pm 0,24 \mathrm{Ba}$ \\
\hline \multirow[t]{3}{*}{ Janeiro a março } & Capim-marandu & Lignina & 2,07 & $\pm 0,16 \mathrm{Cb}$ & $2,35 \pm$ & $\pm 0,06 \mathrm{Bab}$ & 2,44 & $\pm 0,35 \mathrm{Ba}$ \\
\hline & Capim-tifton 85 & & 3,55 & $\pm 0,33 \mathrm{Ba}$ & $3,65 \pm$ & $\pm 0,23 \mathrm{Aa}$ & 2,74 & $\pm 0,12 \mathrm{Bb}$ \\
\hline & Capim-tanzânia & & 2,16 & $\pm 0,16 \mathrm{Cb}$ & $2,16 \pm$ & $\pm 0,32 \mathrm{Bab}$ & 2,45 & $\pm 0,00 \mathrm{Ba}$ \\
\hline \multirow[t]{3}{*}{ Abril a junho } & Capim-marandu & & 3,03 & $\pm 0,18 \mathrm{Ba}$ & $2,95 \pm$ & $\pm 0,11 \mathrm{Ba}$ & 2,84 & $\pm 0,06 \mathrm{Ba}$ \\
\hline & Capim-tifton 85 & & 4,87 & $\pm 0,26 \mathrm{Aa}$ & $3,52 \pm$ & $\pm 0,11 \mathrm{Ac}$ & 3,90 & $\pm 0,12 \mathrm{Ab}$ \\
\hline & Capim-tanzânia & & 3,45 & $\pm 0,65 \mathrm{Ba}$ & $2,85 \pm$ & $\pm 0,43 \mathrm{Ba}$ & 2,80 & $\pm 0,12 \mathrm{Ba}$ \\
\hline
\end{tabular}

${ }^{1}$ Médias seguidas pela mesma letra, maiúscula na coluna e minúscula na linha, dentro de cada parâmetro, não diferem (P $\left.>0,05\right)$ pelo teste T. FDNcp - fibra em detergente neutro corrigida para cinzas e proteínas; FDA - fibra em detergente ácido; CNF - carboidratos não-fibrosos ou fração A+B1. 
teores de carboidratos não-fibrosos, independentemente da idade de corte avaliada. Apesar dos menores valores de carboidratos totais no período de abril-junho, o capimtanzânia apresentou nesse período maiores concentrações da fração C em comparação ao período de janeiro-março, independentemente da idade de rebrota.

Os menores valores de carboidratos totais, no capimtifton foram obervados no período de abril-junho, quando ocorreram, no entanto, as maiores concentrações da fração C e lignina, aos 28 e 42 dias de rebrota.

Nos meses de janeiro-março, o capim-marandu foi a espécie que apresentou os menores valores de fibra em detergente neutro, fibra em detergente neutro corrigida para cinzas e proteínas, fibra em detergente ácido e fração $\mathrm{B}_{2}$, aos 28 e 35 dias de rebrota, além de menor valor de carboidratos totais, em todas as idades de corte avaliadas. Já o capim-tifton 85 apresentou em janeiro-março os maiores valores de fibra em detergente neutro e fibra em detergente neutro corrigida para cinzas e proteínas, independente da idade de corte, além de maiores valores de fração C e lignina e menores valores de carboidratos não-fibrosos aos 28 e 35 dias de corte, provavelmente em virtude do manejo realizado.

Na época de abril-junho, a fração $C$ e os teores de lignina foram maiores no capim-tifton 85 , enquanto os capins marandu e tanzânia apresentaram valores semelhantes para essas variáveis.

Os menores valores de fibra em detergente neutro, fibra em detergente neutro corrigida para cinzas e proteínas e carboidratos totais no capim-marandu em abril-junho foram obtidos aos 28 dias de corte, mas aumentaram com o avanço da idade de corte. Entretanto, avaliando o capim-tanzânia no mesmo período, a idade de corte aos 35 dias destacou-se por apresentar os menores valores de fibra em detergente neutro, fibra em detergente neutro corrigida para cinzas e proteínas, fibra em detergente ácido e fração $\mathrm{B}_{2}$ e maiores de carboidratos não-fibrosos, com maiores conteúdos de parede celular e menores de carboidratos não-fibrosos observados com a idade de corte aos 28 dias. Também os menores valores de fibra em detergente ácido, fração C e lignina do capim-tifton 85 no período de abril-junho foram obtidos aos 35 dias de rebrota, enquanto os maiores valores foram observados aos 28 dias de idade de corte. Pena et al. (2009), avaliando as características morfogênicas e estruturais e o acúmulo de forragem do capim-tanzânia, submetido a diferentes alturas de corte e intervalos de corte, concluíram que tanto o intervalo quanto a altura de corte podem influenciar o acúmulo e a composição morfológica da forragem produzida, e sua importância relativa varia com a época do ano e o estádio fenológico das plantas.

Esse fato pode ser explicado pelas condições ambientais na época experimental (Tabela 1), uma vez que no período referente ao corte na idade de 28 dias, houve estresse hídrico, gerando acúmulo de material morto. Nos cortes feitos aos 35 e 42 dias, a ocorrência de chuvas melhorou o desenvolvimento das plantas, favorecendo a produção de folhas. Todavia, as temperaturas baixas registradas no período de abril-junho ocasionaram redução da taxa de crescimento e uma floração precoce, elevando a fração caule, o que levou a perda do valor nutritivo.

O crescimento das plantas forrageiras implica aumento de parede celular, como evidenciado no capim-marandu. Esse fato ocorre em detrimento das moléculas orgânicas, nutrientes ou não, que participam ativamente dos processos metabólicos; com a deposição de moléculas orgânicas nãonitrogenadas (celulose, hemicelulose, lignina, etc), ocasionando redução na concentração de compostos nitrogenados (Van Soest, 1994) (Tabela 3).

Os valores de proteína bruta do capim-marandu diminuíram com o aumento da idade de corte nos dois períodos e foram maiores aos 28 dias de rebrota. Todavia, esse efeito não foi observado no capim-tanzânia, que, no período de janeiro-março, apresentou maiores valores aos 35 dias de rebrota. Também no período de abril-junho, destacaram-se as concentrações de proteína bruta do

Tabela 3 - Concentração de proteína bruta (\%) no período de janeiro a março e abril a junho

\begin{tabular}{|c|c|c|c|c|c|}
\hline \multirow[b]{2}{*}{ Éроса } & \multirow[b]{2}{*}{ Espécie } & & \multicolumn{3}{|c|}{ Idade de corte da espécie ${ }^{1}$} \\
\hline & & & 28 & 35 & 42 \\
\hline \multirow[t]{3}{*}{ Janeiro a março } & Capim-marandu & & $16,88 \pm 0,43 \mathrm{Aa}$ & $14,24 \pm 0,25 \mathrm{ABb}$ & $14,08 \pm 0,31 \mathrm{Ab}$ \\
\hline & Capim-tifton 85 & & $11,58 \pm 0,24 \mathrm{Ca}$ & $11,69 \pm 0,37 \mathrm{Ca}$ & $10,93 \pm 0,25 \mathrm{Cb}$ \\
\hline & Capim-tanzânia & Proteína & $9,50 \pm 0,21 \mathrm{Dc}$ & $10,39 \pm 0,21 \mathrm{Da}$ & $10,03 \pm 0,06 \mathrm{Cb}$ \\
\hline \multirow[t]{3}{*}{ Abril a junho } & Capim-marandu & bruta & $13,46 \pm 0,28 \mathrm{Ba}$ & $11,22 \pm 0,17 \mathrm{CDb}$ & $9,88 \pm 0,21 \mathrm{Cc}$ \\
\hline & Capim-tifton 85 & (\% MS) & $13,42 \pm 0,59 \mathrm{Bb}$ & $15,19 \pm 0,18 \mathrm{Aa}$ & $13,44 \pm 0,06 \mathrm{ABb}$ \\
\hline & Capim-tanzânia & & $12,17 \pm 0,18 \mathrm{Cb}$ & $13,56 \pm 0,08 \mathrm{Ba}$ & $12,33 \pm 1,20 \mathrm{Bab}$ \\
\hline
\end{tabular}

\footnotetext{
${ }^{1}$ Médias seguidas pela mesma letra, maiúscula na coluna e minúscula na linha, dentro de cada parâmetro, não diferem ( $\left.\mathrm{P} \geq 0,05\right)$ entre si pelo teste $\mathrm{T}$.
}

2 \% da matéria seca; PB - proteína bruta. 
capim-tanzânia na idade de corte aos 35 dias, mas não diferiu quanto as concentrações obtidas com idade de corte aos 42 dias.

O capim-tifton 85 apresentou, no período de janeiromarço, valores semelhantes de PB entre as idades de corte de 28 e 35 dias, com queda aos 42 dias de rebrota. No período de abril-junho, as maiores concentrações de proteína bruta no capim-tifton 85 foram obtidas aos 35 dias de rebrota.

No período de janeiro-março, o capim-marandu destacou-se pelos maiores valores de proteína bruta entre as espécies avaliadas, independentemente da idade de corte. No período de abril-junho, os menores valores de proteína bruta foram obtidos no capim-tanzânia aos 28 dias de rebrota e no capim-marandu aos 35 e 42 dias de rebrota.

Os maiores valores de proteína bruta no capim-marandu foram observados no período de janeiro-março, em todas as idades de rebrota avaliadas. Ao contrário, os maiores valores de PB nos capins tifton 85 e tanzânia foram observados no período de abril-junho.

Apesar de os valores de proteína bruta encontrados nas espécies forrageiras avaliadas (9,50 a 16,88\%) terem sido superiores ao intervalo crítico de 6-8\% da matéria seca, recomendado para que não ocorra diminuição na eficiência do crescimento microbiano e na capacidade de degradação da fibra (Van Soest, 1994), metade da proteína presente nas forrageiras avaliadas apresentou-se como frações B3 e C (Figura 1).
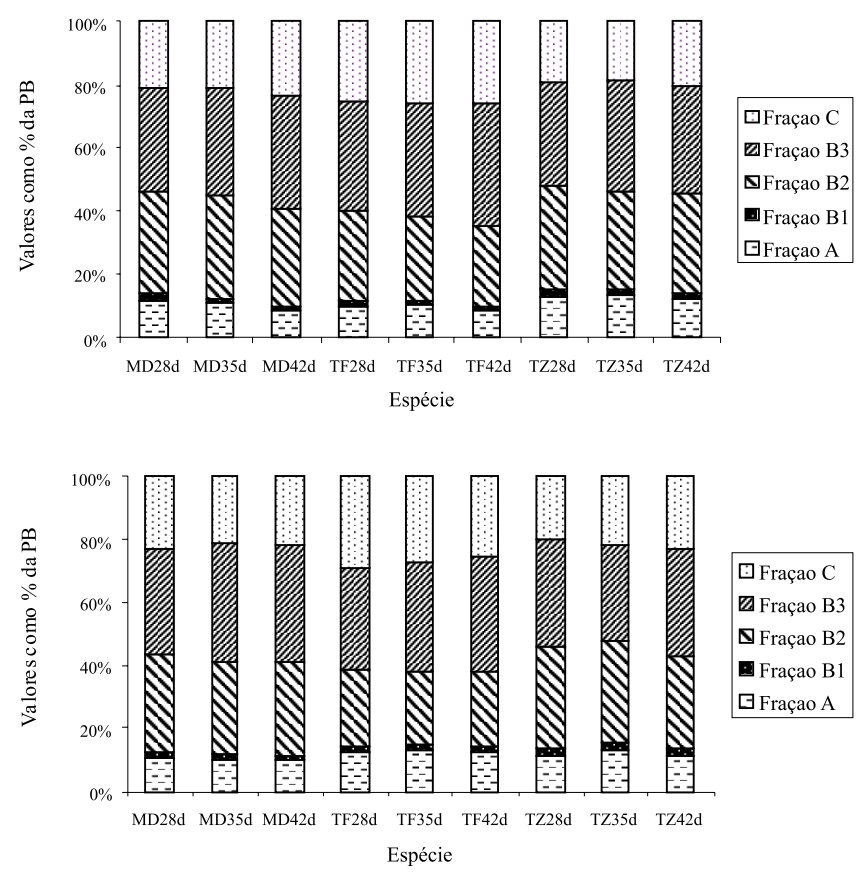

Figura 1 - Fracionamento de proteínas nos períodos de janeiromarço (acima) e abril-junho (abaixo), para os capins TZ (tanzânia), MD (marandu) e TF (tifton 85) em diversas idades de rebrota (28, 35 e 42 dias).
A fração B3 apresenta taxa de degradação muito lenta, pois está associada à parede celular da planta. A fração $\mathrm{C}$ corresponde ao nitrogênio indisponível, e é constituída de proteínas e compostos nitrogenados associados à lignina, aos complexos tânicoproteicos e aos produtos de Maillard, que são altamente resistentes ao ataque das enzimas de origem microbiana e do hospedeiro (Sniffen et al., 1992; Van Soest, 1994). No fracionamento de proteínas das espécies avaliadas, a fração A representou de 9,51 a 12,84\% da PB e a fração B1, de 1,59 a 2,27\% da PB, considerados baixos, mas são tipicamente encontrados em gramíneas tropicais; a fração B2 de 23,77 a 31,84\% da proteína bruta; e as frações B3 e C de 23,77 a 33,40\% e 19,66 a 27,04\% da proteína bruta. Os maiores valores de fração B3 e C foram do capim-tifton 85, possivelmente em resposta ao manejo no período experimental (acúmulo de material morto) e características da espécie.

Nas duas épocas, as frações A, B1 e B2 diminuíram significativamente com o aumento da idade. Esse fato representa menor suprimento de isoácidos, exigidos pelos microrganismos do rúmen (Russell et al., 1992). As frações B3 e C das forrageiras aumentaram com a idade (Figura 1).

Os resultados referentes à digestibilidade in vitro da matéria seca e digestibilidade in vitro da matéria orgânica das espécies forrageiras avaliadas (Tabela 4) estão correlacionados às concentrações de parede celular e de carboidratos não-fibrosos (Tabela 2) e ao fracionamento de proteínas (Figura 1).

O capim-marandu destacou-se no período de janeiromarço por apresentar os maiores valores de digestibilidade in vitro da matéria seca e digestibilidade in vitro da matéria orgânica, porém não diferindo do capim-tifton 85 aos 35 dias e capim-tanzânia aos 42 dias de rebrota. Também no período de abril-junho, o capim-marandu destacou-se por apresentar os maiores valores de digestibilidade in vitro da matéria orgânica aos 28 dias de rebrota e não diferiu do capim-tifton 85 nem do capimtanzânia nas demais épocas de corte.

A digestibilidade in vitro da matéria seca e da matéria orgânica dos capins marandu e tifton 85 não diferiu entre os períodos de janeiro-março e abril-junho. A digestibilidade in vitro da matéria seca do capim-tanzânia aos 35 dias de rebrota foi menor no período de janeiro-março em comparação a abril-junho. Também, foi observado menores valores de digestibilidade in vitro da matéria orgânica do capimtanzânia aos 28 e 35 dias de rebrota nos meses de janeiromarço comparado a abril-junho.

A digestibilidade do capim-marandu reduziu de acordo com estágios fisiológicos mais avançados nas duas épocas avaliadas, todavia, nas outras espécies esse comportamento não foi claro. O manejo inadequado do 
Tabela 4 - Coeficientes de digestibilidade in vitro da matéria seca e matéria orgânica no período de janeiro a março e abril a junho

\begin{tabular}{|c|c|c|c|c|c|}
\hline & Item & Idade de corte das espécies ${ }^{1}$ & & & \\
\hline Época & Espécie & & 28 & 35 & 42 \\
\hline \multirow[t]{3}{*}{ Janeiro a março } & Capim-marandu & & $70,65 \pm 0,07 \mathrm{Aa}$ & $64,30 \pm 0,03 \mathrm{Ab}$ & $61,60 \pm 0,42 \mathrm{Ac}$ \\
\hline & Capim-tifton 85 & & $47,80 \pm 6,65 \mathrm{Cab}$ & $53,05 \pm 0,35 \mathrm{Aa}$ & $47,15 \pm 1,77 \mathrm{Bb}$ \\
\hline & Capim-tanzânia & DIVMS (\%) & $48,85 \pm 0,49 \mathrm{Ca}$ & $48,30 \pm 5,94 \mathrm{Ba}$ & $53,00 \pm 4,24 \mathrm{ABa}$ \\
\hline \multirow[t]{3}{*}{ Abril a junho } & Capim-marandu & & $60,70 \pm 1,84 \mathrm{ABa}$ & $58,00 \pm 2,26 \mathrm{ABab}$ & $56,85 \pm 0,21 \mathrm{ABb}$ \\
\hline & Capim-tifton 85 & & $47,30 \pm 0,71 \mathrm{Cc}$ & $53,40 \pm 0,14 \mathrm{ABa}$ & $52,70 \pm 0,28 \mathrm{ABb}$ \\
\hline & Capim-tanzânia & & $57,25 \pm 0,35 \mathrm{BCb}$ & $61,65 \pm 0,07 \mathrm{Aa}$ & $57,80 \pm 1,84 \mathrm{Ab}$ \\
\hline \multirow[t]{3}{*}{ Janeiro a março } & Capim-marandu & & $67,25 \pm 0,21 \mathrm{Aa}$ & $60,00 \pm 0,02 \mathrm{Ab}$ & $56,90 \pm 0,71 \mathrm{Ac}$ \\
\hline & Capim-tifton 85 & & $44,20 \pm 5,80 \mathrm{Cab}$ & $48,75 \pm 0,35 \mathrm{ABa}$ & $43,10 \pm 1,27 \mathrm{Bb}$ \\
\hline & Capim-tanzânia & DIVMO (\%) & $45,35 \pm 1,20 \mathrm{Ca}$ & $44,75 \pm 5,59 B a$ & $48,60 \pm 4,24 \mathrm{ABa}$ \\
\hline \multirow[t]{3}{*}{ Abril a junho } & Capim-marandu & & $55,70 \pm 1,56 \mathrm{Aa}$ & $53,45 \pm 2,33 \mathrm{ABab}$ & $51,70 \pm 0,01 \mathrm{ABb}$ \\
\hline & Capim-tifton 85 & & $43,45 \pm 0,92 \mathrm{Cc}$ & $47,20 \pm 0,14 \mathrm{ABb}$ & $48,85 \pm 0,64 \mathrm{ABa}$ \\
\hline & Capim-tanzânia & & $52,95 \pm 0,49 \mathrm{Bb}$ & $58,95 \pm 0,78 \mathrm{Aa}$ & $54,30 \pm 1,70 \mathrm{ABb}$ \\
\hline
\end{tabular}

${ }^{1}$ Médias seguidas pela mesma letra, maiúscula na coluna e minúscula na linha, dentro de cada parâmetro, não diferem (P>0,05) pelo teste T.

${ }^{2}$ DIVMS - Digestibilidade in vitro da matéria seca; DIVMO - Digestibilidade in vitro da matéria orgânica.

capim-tifton 85 propiciou a produção de forragem com altos conteúdos de constituintes da parede celular (Tabela 2), o que resultou em baixos valores de digestibilidade nas avaliações (Tabela 4).

O maior coeficiente de digestibilidade da MS e MO no período de janeiro-março foi observado, de maneira geral, no capim-marandu, resultado coerente, uma vez que esta gramínea apresentou as menores concentrações de fibra em detergente neutro, fibra em detergente neutro corrigida para cinzas e proteína, fibra em detergente ácido e fração $\mathrm{B}_{2}$ dos carboidratos e maiores concentrações de proteína bruta e carboidratos não-fibrosos neste período. O capim-marandu também promoveu os melhores parâmetros de cinética de fermentação e taxas de degradação no período de janeiro a março em comparação aos capins tanzânia e tifton 85 (Velásquez et al., 2009). À medida que a idade fisiológica da planta avançou, aumentaram as porcentagens de celulose, hemicelulose e lignina, reduzindo a proporção dos nutrientes potencialmente digestíveis e a digestibilidade.

Alguns autores têm estabelecido relação entre anatomia, composição química e digestibilidade de gramíneas forrageiras. Correlações altamente significativas entre a proporção de tecidos individuais, ou em combinação, e as entidades nutricionais têm sido observadas (Wilson et al., 1989; Queiroz et al., 2000b). Em geral, os constituintes fibrosos (FDN, FDA e lignina) são correlacionados negativamente à digestibilidade (Wilson et al., 1983; Weiss, 1994; Queiroz et al., 2000a; Alves de Brito et al., 2003).

\section{Conclusões}

Independentemente da idade de corte, o capim-marandu apresenta no período de janeiro a março melhor valor nutritivo em comparação aos capins tanzânia e tifton 85. No entanto, no período de abril a junho, o capim-tanzânia se destaca pela menor concentração de componentes da parede celular e valores superiores de carboidratos não-fibrosos, assim como a digestibilidade in vitro da matéria seca e da matéria orgânica, que passam a ser maiores em comparação aos capins marandu e tifton 85 .

\section{Referências}

ALVES DE BRITO, C.J.F.; RODELLA, R.A.; DESCHAMPS, F.C. Perfil químico da parede celular e suas implicações na digestibilidade de Brachiaria brizantha e Brachiaria humidicola. Revista Brasileira de Zootecnia, v.32, n.8, p.1835-1844, 2003.

ASSOCIATION OF OFFICIAL ANALYTICAL CHEMISTS AOAC. Official methods of analysis. 12.ed. Washington: AOAC International, 1990. 1098p.

BRÂNCIO, P.A.; NASCIMENTO JR., D.; EUCLIDES, V.P.B. et al. Avaliação de três cultivares de Panicum maximum Jacq. sob pastejo. composição química e digestibilidade da forragem. Revista Brasileira de Zootecnia, v.31, n.4, p.1605-1613, 2002.

BUXTON, D.R.; REDFEARN D.D. Plant limitations to fiber digestion and utilization. Journal Nutrition, v.127, p.814-818, 1997.

GETACHEW, G.; BLUMMEL, M.; MAKKAR, H.P.S. et al. In vitro gas measuring techniques for assessment of nutritional quality of feeds: a review. Animal Feed Science and Technology, v.72, n.3-4, p.261-281, 1998.

LICITRA, G.; HERNANDEZ, T.M.; VAN SOEST, P.J. Standardization of procedures for nitrogen fractionation of ruminant feeds. Animal Feed Science and Technology, v.57, n.4, p.347-358, 1996.

McDOUGAL, E.I. Studies on ruminal saliva. 1. The composition and output of sheep's saliva. Biochemical Journal, v.43, n.1, p.99-109, 1949.

MERTENS, D.R. Regulation of forage intake. In: FAHEY Jr., G.C.; COLLINS, M.; MERTENS, D.R. et al. (Eds.). Forage quality evaluation and utilization. Nebraska: American Society of Agronomy, Crop Science of America, Soil Science of America, 1994. p.450-493.

PENA, K.S.; NASCIMENTO JR., D.; SILVA, S.C. et al. Características morfogênicas, estruturais e acúmulo de forragem 
do capim tanzânia submetido a duas alturas e três intervalos de corte. Revista Brasileira de Zootecnia, v.38, n.11, p.2127-2136, 2009.

QUEIROZ, D.S.; GOMIDE, J.A.; MARIA, J. Avaliação da folha e do colmo de topo e base de perfilhos de três gramíneas forrageiras. 1. Digestibilidade in vitro e composição química. Revista Brasileira de Zootecnia, v.29, n.1, p.53-60, 2000a. QUEIROZ, D.S.; GOMIDE, J.A.; MARIA, J. Avaliação da folha e do colmo de topo e base de perfilhos de três gramíneas forrageiras. 2. Anatomia. Revista Brasileira de Zootecnia, v.29, n.1, p.61-68, 2000b.

REIS, R.A.; MELO G.M.P.; BERTIPAGLiA L.M.A. et al. Otimização da utilização da forragem disponível através da suplementação estratégica. In: REIS R.A.; SIQUEIRA, G.R.; BERTIPAGLIA, L.M.A. et al. (Eds.). Volumosos na produção de ruminantes. Jaboticabal: Funep, 2005. p.187-238.

RUSSELL, J.B.; O'CONNOR, J.D.; FOX, D.G. et al. A net carbohydrate and protein system for evaluating cattle diets: I. Ruminal fermentation. Journal of Animal Science, v.70, n.12, p.3551-3561, 1992.

SNIFFEN, C.J.; O'CONNOR, D.J.; VAN SOEST, P.J. et al. A net carbohydrate and protein system for evaluating cattle diets: carbohydrate and protein availability. Journal of Animal Science, v.70, n.12, p.3562-3577, 1992.

STATISTICAL ANALYSIS SYSTEMS - SAS. User's guide . Version 8. 1.ed. Cary: 2001. 956p.

TILLEY, J.M.A.; TERRY, R.A. A two stage technique for in vitro digestion of forages crops. Journal of the British Grassland Society, v.18, p.104-111, 1963.

VAN SOEST, P.J. Nutritional ecology of the ruminant. 2.ed. Ithaca: Cornell University Press, 1994. 476p.
VAN SOEST, P.J.; ROBERTSON, J.B. Analysis of forages and fibrous foods. Ithaca: Cornell University, 1985. 202p.

VELÁSQUEZ, P.A.T.; BERCHIELLI, T.T.; REIS, R.A. et al. Cinética da fermentação e taxas de degradação de forrageiras tropicais em diferentes idades de corte estimadas pela técnica de produção de gases in vitro. Revista Brasileira de Zootecnia, v.38, n.9, p.1695-1705, 2009.

WEISS, W.P. Estimation of digestibility of forages by laboratory methods. In: FAHEY JR., G.C.; COLLINS, M.; MERTENS, D.R. et al. (Eds.). Forage quality evaluation and utilization. Nebraska: American Society of Agronomy, Crop Science of America, Soil Science of America, 1994. p.644-651.

WILSON, J.R. Organization of forage plant tissues. In: JUNG, H.G., BUXTON, D.R., HATFIELD, R.D. et al. (Eds.) Forage cell wall structure and digestibility. Madison: American Society of Agronomy, Crop Science Society of America, Soil Science Society of America, 1993. p.1-32.

WILSON, J.R. Structural and anatomical traits of forage influencing their nutritive value for ruminants. In: SIMPÓSIO INTERNACIONAL SOBRE PRODUÇÃO ANIMAL EM PASTEJO, 1997, Viçosa, MG. Anais... Viçosa, MG: Universidade Federal de Viçosa, 1997. p.173-208.

WILSON, J.R.; ANDERSON, K.L.; HACKER, J.B. Dry matter digestibility in vitro of leaf and stem of buffel grass (Cenchrus ciliares) and related species and its relation to plant morphology and anatomy. Australian Journal Agriculture Research, v.40, n.2, p.281-291, 1989.

WILSON, J.R.; BROWN, R.H.; WINDHAM, W.R. Influence of leaf anatomy on dry matter digestibility of $\mathrm{C} 3, \mathrm{C} 4$, and $\mathrm{C} 3 / \mathrm{C} 4$ intermediate types of Panicum species. Crop Science, v.23, n.1, p.141-146, 1983. 